\title{
Using DANP-mV Model to Improve the Paid Training Measures for Travel Agents amid the COVID-19 Pandemic
}

\author{
Chui-Hua Liu ${ }^{1, *}$ and Bochner Liu ${ }^{2}$ \\ 1 Department of Tourism \& Hospitality, Kainan University, Taoyuan City 33857, Taiwan \\ 2 IMBA Program, Department of Economics, Antai College of Economics and Management (ACEM), \\ Shanghai Jiao Tong University, Shanghai 200240, China; pai314@sjtu.edu.cn \\ * Correspondence: liu32lee@mail.knu.edu.tw
}

Citation: Liu, C.-H.; Liu, B. Using DANP-mV Model to Improve the Paid Training Measures for Travel Agents amid the COVID-19 Pandemic. Mathematics 2021, 9, 1924. https://doi.org/10.3390/math9161924

Academic Editor: Óscar Valero Sierra

Received: 9 June 2021

Accepted: 3 August 2021

Published: 12 August 2021

Publisher's Note: MDPI stays neutral with regard to jurisdictional claims in published maps and institutional affiliations.

Copyright: (C) 2021 by the authors. Licensee MDPI, Basel, Switzerland. This article is an open access article distributed under the terms and conditions of the Creative Commons Attribution (CC BY) license (https:// creativecommons.org/licenses/by/ $4.0 /)$.

\begin{abstract}
Due to the COVID-19 pandemic bringing travel to a standstill, an initiative of paid training for travel agencies was launched by the government. The purpose of this research is to improve the effectiveness of this measure, which is fundamental to the next tourism crisis management. Based on the related theories of tourism crisis management, organizational learning, and behavior adaption, the DANP-mV model developed an evaluation system for examining the training measure. The result of an influential network relationship map (INRM) shows that using influential effects, the "policy object" dimension and its criterion "subsidiary" should be the first improvement priority. To effectively achieve the aspiration level, the gap values point out "training courses" dimension and its criterion "excellent services" are first to improve. An action plan is produced containing all the findings and made available for easy indexing. It may contribute to the current measure improvements. Therefore, this innovative approach could help decision makers with tourism crisis policy making and help the sector with evolving learning readiness to remain sustainable.
\end{abstract}

Keywords: DANP-mV model; tourism crisis management; organizational learning; behavior adaption

\section{Introduction}

The COVID-19 pandemic has brought tourism industry to a standstill. This desperation creates tremendous revenue and job losses and brings actual and deep worry for millions of households and individuals globally [1-3]. During this global pandemic, Taiwanese travel agencies are no exception. It was estimated that over $90 \%$ of travel agencies are struggling for survival, and 108,197 employees are faced with job losses or lay-offs [4]. The crisis has given rise to a feeling of fear and insecurity in individuals and industries as a whole. How to evolve this challenge [3] toward continuity has emerged as the major goal of the sustainable tourism sector.

Crises can be valuable when they result in important learning outcomes, suggested by the research on organization learning and crises management [5,6]. As new knowledge gives feedbacks for future practices [7], the leaning readiness would turn crisis into power. Thus, organizational learning is regarded as powerful in improving the efficiency of crisis management strategies [8]. Regarding the main type of government strategy/policy in response to crises, the literature points out that it is the provision of human resources and financial assistance, in particular, toward the tourism industry $[9,10]$.

The Taiwanese tourism authority thus launched an initiative of paid training for travel agencies. This subsidiary measure was initiated to upgrade human resources, and the travel agencies were given the direct financial support for pandemic shutdown within the context of organization learning. The measure features free courses by hourly payment for a maximum of $120 \mathrm{~h}$ per month. This amount is transferred to each travel agency [11]. However, there is no course formation. Under the guidelines of the tourism authority, courses could be arranged in a variety of ways by each host organization. Elaborate 
evaluation on the effectiveness of the program is urgently needed in the current resolution phase.

Moreover, previous studies dealing with the tourism sector of crisis management tended to focus on airlines, large tour companies, and hotels [12]. Few of them considered small businesses [13] such as travel agencies. Others shed light on organization learning but did not proceed to effectively learn from crisis circumstances or propose any learning mechanisms [12,13]. Liu et al. [14] suggested that for improving tourism policy implementation, managing all interdependently (criterion to other criteria) and criteria individually (criterion itself) is an eventually effective approach.

Therefore, this research investigates the effectiveness of the current policy measures and the gaps cited in the above literature. Using the Taiwanese empirical case, it is purposed at (1) examining the related factors of the paid training measure policy; (2) understanding the interrelations between the policy object, training courses, and adaption behavior; (3) proposing profound analysis of potential effectiveness by applying a multi-variant technique to solve the complex response from the relationships between variables; (4) and presenting an improvement plan to help individuals, the travel agency sector, and governments to better manage tourism crisis measure.

To evaluate the effectiveness of the measure, the evaluation system was first established on the above theoretical basis. The innovative DEMATEL-based ANP and modified VIKOR (DANP-mV) technique was used to find the influential relationships the gaps between actual/desired effectiveness level between and criteria. The DANP-mV can be considered as a multiple criteria decision-making (MCDM) robot combination algorithm [15-18]. Because the research problem is inherently complicated with interactions beyond linear relationships, the model is accordingly suitable for this research for (1) DEMATEL to clarify interrelated criteria, (2) DANP to calculate influence weights, and (3) the modified VIKOR to evaluate gap values.

The remaining content of this article will be presented in following order. In Section 2, the previous literature regarding tourism crisis management, organizational learning, and crisis adaption behavior are assessed. In Section 3, the innovative DANP-mV evaluation system is established. In Section 4, the empirical case of Taiwanese paid training measures for travel agents amid the COVID-19 pandemic demonstrates the feasibility of the proposed system. Lastly, the conclusions are demonstrated in Section 5.

\section{Literature Review}

\subsection{Organizational Learning and Governmental Tourism Crisis Management Policy}

Organizational learning aims to improve the knowledge of organizations. The enhancement is a prerequisite to deal with disasters and crises [19]. Some scholars emphasized individual learning in organizations because individuals are active agents [20]. Others argued that individual learning is not as complex and dynamic as organizational learning [21]. Nevertheless, Argyria argued that it is critical to account the interaction between individuals and organizational units [22]. Thus, it can establish new knowledge for organizational learning practitioners. Regardless the differences, all these studies have commonly recognized the learning effectiveness of crisis management [8,23-30]. For crisis management, the knowledge has contributed to the reevaluation of the latest applied theories and concepts and has led to an improvement [8].

On the governmental level, having a defined plan to promote swift recovery is urgent in managing tourism crises [1-3]. In usual, the government can practice new financial, economic, and administrative measures or programs directed at the tourism industry to ease the harmful impacts. The measures include providing low-interest loans and subsidies, returning quality performance deposits, and waiving taxes [3,31-33]. Considering the effectiveness of learning and government subsidiaries, the tourism authority of Taiwan launched a program of paid job training for travel agencies amid the business shutdown for COVID-19 in 2020. 
In implementation, tourism and related organizations dealt with crisis on the basis of specific crisis-designed guidelines [7]. Measures that are particular to travel agencies are a paid training program. The Taiwanese tourism authority reported that the policy's objects were [11]: (1) subsidy, (2) transformation, (3) knowledge, (4) and interexchange. Under these general objects, learning activities were divided into seven categories for host organizations to follow (Table 1). According to the guidelines, various courses could be arranged. This also raised the question of what courses are appropriate and effective for this subsidized organizational learning.

Table 1. The dimensions and criteria of the paid training measure.

\begin{tabular}{|c|c|c|c|}
\hline Dimensions & Criteria & Context & Sources \\
\hline \multirow{4}{*}{$\begin{array}{c}\mathrm{D}_{1} \\
\text { Policy object }\end{array}$} & $\mathrm{C}_{11}$ Subsidy & $\begin{array}{l}\text { Using training attendance hourly wages as } \\
\text { compensation to keep the industry running, } \\
\text { easing employees tension, and encouraging } \\
\text { market confidence }\end{array}$ & \multirow{4}{*}[1-3,7,8,11,32,33]{} \\
\hline & $\mathrm{C}_{12}$ Transformation & $\begin{array}{c}\text { Training program to help travel agencies step } \\
\text { forward towards sector transformation, } \\
\text { upgrade, and digital marketing }\end{array}$ & \\
\hline & $\mathrm{C}_{13}$ Knowledge & $\begin{array}{l}\text { Learning to update professional knowledge, } \\
\text { skills, and marketing competence }\end{array}$ & \\
\hline & $\mathrm{C}_{14}$ Interexchange & $\begin{array}{l}\text { Program for an interexchange channel with } \\
\text { vertical-horizontal industries }\end{array}$ & \\
\hline \multirow{3}{*}{$\begin{array}{l}\mathrm{D}_{2} \\
\text { Training courses }\end{array}$} & $\mathrm{C}_{21}$ Tech travel & $\begin{array}{l}\text { Courses including }{ }^{124} \text { technology application } \\
\text { on travel industry, }{ }^{124} \text { digital marketing, } \\
{ }^{124} \text { tour itinerary and digital marketing, and } \\
{ }^{12} \text { labor / transformation of travel industry }\end{array}$ & \multirow{3}{*}[11,34-40]{} \\
\hline & $\mathrm{C}_{22}$ Upgrade industry & $\begin{array}{l}\text { Courses including }{ }^{126} \text { public } \\
\text { relations/cross-industry allies, }{ }^{12} \text { thinking } \\
\text { out of the box/innovation, }{ }^{25} \text { fit, wellness and } \\
\text { sound employee, }{ }^{15} \text { travel crisis management, } \\
\text { and }{ }^{35} \text { consumer rights }\end{array}$ & \\
\hline & $\mathrm{C}_{23}$ Excellent services & $\begin{array}{l}\text { Course including }{ }^{17} \text { field studies-outdoor } \\
\text { guiding/in coach interpretation, } \\
{ }^{135} \text { communication skills with clients, } \\
{ }^{135} \text { complaint management }\end{array}$ & \\
\hline \multirow{3}{*}{$\begin{array}{l}\mathrm{D}_{3} \\
\text { Behavior adaption }\end{array}$} & $\mathrm{C}_{31}$ Recover & Retrieving pre-crisis status & \multirow{3}{*}[20,40-54]{} \\
\hline & $\mathrm{C}_{32}$ Regain & $\begin{array}{c}\text { Regaining one's balance with new skills } \\
\text { and resources }\end{array}$ & \\
\hline & $\mathrm{C}_{33}$ Retain & Remaining in current status & \\
\hline
\end{tabular}

Note: (a). Fourteen training courses were developed according to seven categories set by the government and extracted as three factors (dimensions) by principal component analysis $(n=240)$. (b) Category number in italics in upper-left corner of each course, for instance, ${ }^{135}$ complaint management, denotes course in the contexts of Categories 1, 3, and 5.

\subsection{Tourism Crisis Management and Travel Agency Sector}

The tourism industry is vulnerable to crises [34,36]. From a social perspective, crises are defined as disruptions that affect a system physically. Different from disasters, crises are situations which may cause long-term impairment and huge loss of life to the impacted societies [36,37]. Using this definition, tourism crises can be defined as the events which could endanger the standard operations of a business or hurt a destination in the tourism industry [38]. These occurrences may threaten the standard operation and practice of tourism-related businesses. They cause a series of threats and losses, such as an economic depression in the local travel and tourism industry, an interruption in the steadiness of business operations for local travel, and the decrease in tourist arrivals and expenditures [3,4]. 
To manage tourism crises, studies have summarized critical factors for crisis recovery. Campiranon and Scott [53] summed up five success factors: 1. Crisis management and recovery plan, 2. Personnel management, 3. Recovery promotion, 4. Market segmentation, and 5. Recovery collaboration. Boin and McConnell [36] also proposed five essentials in a timeline: prevention, planning, response, recovery, and learning. Facing the unprecedented COVID-19 pandemic, there is no prevention precedent. Planning and recovery, personnel management, and learning are the current responses. This is particularly true to a travel agency. A travel agency is usually defined by its small size, lack of resources, and inability to analyze potential threats $[12,34,35]$. Personnel management is urgent when the business is shut down for a travel agency.

In times of crisis, human resource management strategies are required in the resolution phase. Turning to travel agencies, learning, human resources, and government assistance [39] should be integrated to induce a proper learning context that is specific for themselves. In co-operating the policy objects of the government, travel agent courses are categorized into: (1) professional skills, (2) upgrade and transformation preparation, (3) advanced awareness of security and consumer rights, (4) acknowledgement of digital and target marketing, (5) understanding national tourism policy, (6) access to alliances with local industries, and (7) field study [11].

\subsection{Crisis, Learning, and Adaption Behavior}

From a psychological perspective, the term "crisis" has many definitions. Most academics agree that a crisis in human society refers to: (1) any occurrence that impacts normal life (2) but cannot be solved in a usual way, (3) thus immobilizing one's life pattern (4) and causing a disequilibrium and breakdown status [40-43]. Accordingly, the COVID-19 pandemic meets all these definitions. The desperation it has being brought to human society is unprecedented.

However, humans are born to adapt and strive for equilibrium to get through crises [44] Scholars believe that every crisis is an opportunity prompting human revolution. This helps transform the crisis into something better [45-47]. Plans for crises and disasters can be transferred (via channel), translated (for understanding), and transformed (by application) into relevant knowledge [41-53]. So, humans learned that knowledge may optimize responses. These valuable learning outcomes created learning readiness for effective crisis management $[5,6]$. Accordingly, learning assumed may change one's behavior positively.

In this context, humans learn to turn crises into opportunities. However, due to individual differences, different adaptation results may occur. Regarding how learning leads to changes of the behavior, it associates in three different statuses as suggested by social-psychological academics [20,41-43]. They are: (1) recover to pre-crisis status, (2) regain one's balance with new skills and resources, and (3) retain the current situation $[44,53]$. This may be used to interpret behavioral changes after taking the training measures of Taiwanese travel agents, who are currently stranded by COVID-19.

\section{Methodology}

\subsection{DANP-mV Model}

The DANP-mV Model is considered as an effective compromise solution technique while decision making [15-18]. Originated in MCDM (Multi Criteria Decision Making) [54], the DANP-mV has been applied to many fields, including tourism fields [55]. The model was verified for solving challenges with contradictory, complex, and dynamic criteria. The model contains three novel methods as follows. 
The first is DEMATEL [56-59]. It was assumed that every criterion is structurally hierarchical and independent while simultaneously exerting responding effects. Using matrices and applying mathematical theories, these effects can be derived. Consequently, human thoughts can then be transformed into a geometrical map. It is labeled "the influential network relations map" (INRM). The INRM illustrates the network relationships of criteria to show complicated relationships between them in a co-ordinate space. This makes the model super in comparison to the traditional analytical tools.

The second is the DEMATEL-based ANP (DANP). It is combined with Saaty's ANP [60] to derive the influential weights of the criteria in the DEMATEL procedure. Then, the influential weights can be further used by the modified VIKOR technique to calculate the gap between real/aspirational levels. DANP was verified as an evolutional joint method in literature [15-18,55].

The third is the modified VIKOR. It is a compromise solution ranking method by calculating the gap value of each criterion to the aspiration level [61-64]. By setting up the aspiration level (the benchmark of the best option), the average overall performance gaps (i.e., mean of group utility derived from the sum of all individual regrets), and the maximal gap (i.e., the maximum regret), the specific criterion can be estimated more precisely. Comparing to the traditional VIKOR, the modified VIKOR only applies the basic positiveideal point, the maximum-minimum concept, and the negative-ideal point. Therefore, it can avoid "picking the best apple from a barrel of rotten apples" scenario [15-18,55].

Combining the DEMATEL, the DEMATEL-based ANP, and the modified VIKOR, the innovative DANP-mV model became a well-rounded technique which is especially valuable in solving comprehensive improvement strategy problems. In this article, this approach allows for the contribution of the research purposes by (1) applying DEMATEL to explain interrelated criteria of the relationships associated with the paid training measures; (2) applying DANP to derive criteria's influential weights; (3) applying the modified VIKOR to access the performance of the criteria; (4) being an inherently feasible solution which can report measure improvement (Figure 1).

\subsection{Sampling and Collection}

On the basis of the literature review, a structural questionnaire of 3 dimensions (including policy object, training courses, and behavioral adaption) with 10 criteria was developed. A five-point scale is used for the measurement, ranging from " 0 not at all influential" to " 4 extremely influential" in the DANP part. As in the modified VIKOR, an 11-point scale was used, ranging from " 0 extremely disagree" to "10 extremely agree". Then, the research was designed using two stages to collect data.

In the first stage, a pilot test was conducted with 240 trainees (separately from four terms, April to September 2020, via Google survey after one week of their training completion. Cronbach's $\alpha$ of the items was greater than 0.78 . This stage verified the reliability of the instrument [65].

In the second stage, the expert questionnaire of DANP-mV was delivered to 20 group leaders of 3 training terms from May to September. To make inferences regarding a population, this study used a representative sampling strategy [66]. The sampled trainee experts had to meet the additional requirements: (1) full participation to paid training without any leaves and (2) being an active correspondent between trainees and host organization. The duration of each interview (using social media because of the pandemic) was about 20 to $25 \mathrm{~min}$. The consistency test displayed significant confidence at $96.65 \%$ (>95\%). The gap error was 3.4\%, which indicates a significant consensus among the participants. 


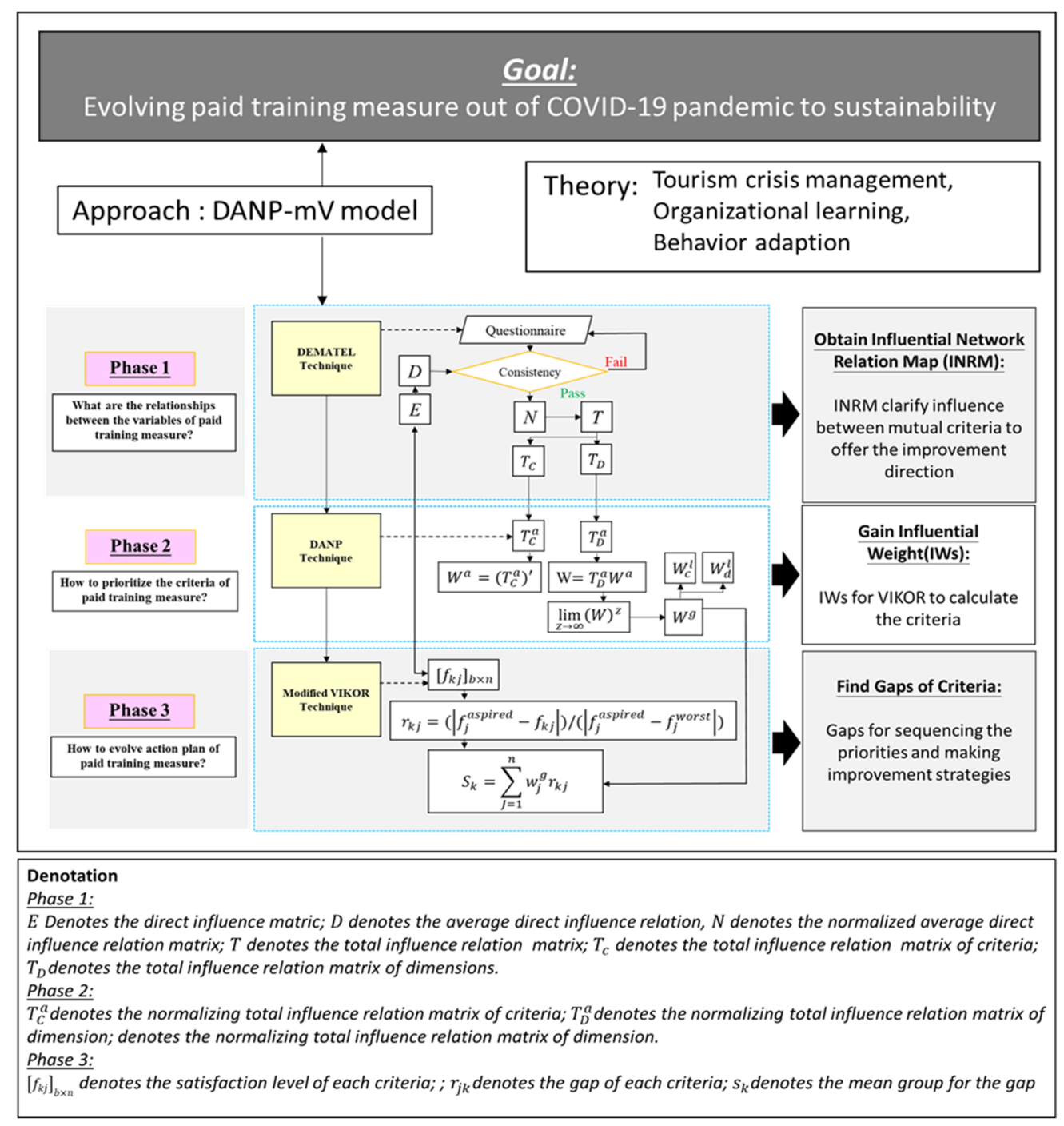

Figure 1. Theoretical conceptual framework and research procedure.

\subsection{Research Procedure}

The DANP-mV model here in this study was preceded via three phases [15-18]:

\subsubsection{The First Phase: To Obtain INRM by DEMATEL}

The goal of this phase was to untie the mutual influence between the criteria of the paid training program. Through the data collection of the questionnaire interview, the opinions of industry experts were well integrated and transformed into the initial matrix by pairwise comparison method. Then, the relation matrix of the total influence of dimensions $T_{D}$ and criteria $T_{C}$ were derived by applying DEMATEL method to obtain the INRM. The calculation steps are shown below.

Step 1: Establishing the direct influence relation matrix $E$.

Using the questionnaire with a scale ranging from 0 , no influence, to 4 , extreme influence, the data was thus obtained. Then, the pairwise comparison method was used to evaluate the degree of influence of the criteria. This is to evaluate the degree of each criterion $i$ affects each criterion $j$. The matrix is an $n \times n$ nonnegative matrix. Using the opinions of $H$ experts, the direct influence relation matrix $E$ is shown in Equation (1). The 
direct influence relation matrix from all experts is $E^{h}=\left[e_{i j}^{h}\right]_{n \times n}$, where $h=1,2, \ldots, H$ $E^{1}, \ldots E^{h}, \ldots, E^{H}$.

$$
E=\left[\begin{array}{ccccc}
e_{11} & \ldots & e_{1 j} & \ldots & e_{1 n} \\
\vdots & & \vdots & & \vdots \\
e_{i 1} & \ldots & e_{i j} & \ldots & e_{i n} \\
\vdots & & \vdots & & \vdots \\
e_{n 1} & \ldots & e_{n j} & \ldots & e_{n n}
\end{array}\right]
$$

Step 2: Constituting the average direct influence relation matrix $D$

The average direct influence relation matrix $D$ is defined as $d_{i j}=\frac{1}{H} \sum_{h=1}^{H} e_{i j}^{h}$, representing the average scores of the $\mathrm{H}$ experts. This matrix calculates the influence degree that the criterion exerts on or received from each other, as shown in Equation (2):

$$
D=\left[\begin{array}{ccccc}
d_{11} & \ldots & d_{1 j} & \ldots & d_{1 n} \\
\vdots & & \vdots & & \vdots \\
d_{i 1} & \ldots & d_{i j} & \ldots & d_{i n} \\
\vdots & & \vdots & & \vdots \\
d_{n 1} & \ldots & d_{n j} & \ldots & d_{n n}
\end{array}\right]
$$

Step 3: Examining consensus.

Regarding the level of experts' consensus, the value of consensus should be estimated and calculated by Equation (3). In common, the threshold of the average gap ratio is $5 \%$ to have a confidence level above $95 \%$.

$$
\text { Averagegap - ratioinconsensus }(\%)=\frac{1}{n(n-1)} \sum_{i=1}^{n} \sum_{j=1}^{n}\left(\left|d_{i j}^{H}-d_{i j}^{H-1}\right| / d_{i j}^{H}\right) \times 100 \%
$$

Step 4: Formulating the normalized average direct influence relation matrix $N$

Hereby, the matrix $D$ is first normalized. Then, the matrix $N$ can be derived by Equations (4) and (5). Until then, all principal diagonal criteria are equal to 0.

$$
\begin{gathered}
N=b \times D \\
b=\min \left\{\frac{1}{\max _{1 \leq i \leq n} \sum_{j=1}^{n} d_{i j}}, \frac{1}{\max _{1 \leq j \leq n} \sum_{i=1}^{n} d_{i j}}\right\}
\end{gathered}
$$

Step 5: Constructing the total influence relation matrix $T$.

A series of decreases emerges in the indirect effects of criteria with the powers of the matrix $N$, e.g., $N^{2}, \ldots, N^{\infty}$ and $\lim _{q \rightarrow \infty} N^{q}=[0]_{n \times n}$ for $\lim _{q \rightarrow \infty} N^{q}=[0]_{n \times n}$, where $I$ is a $n \times n$ unit matrix. Therefore, the total influence relation matrix $T$ is a $n \times n$ matrix. It is thus defined as $T=\left[t_{i j}\right]_{n \times n^{\prime}} i, j=1,2, \ldots, n$ and shown in Equation (6):

$$
\begin{aligned}
& T=N+N^{2}+\ldots+N^{q}=\mathrm{N}\left(I+N+N^{2}+\ldots+N^{q-1}\right) \\
& =\mathrm{N}\left(I+N+N^{2}+\ldots+N^{q-1}\right)(I-N)(I-N)^{-1}=\mathrm{N}(I-N)^{-1} \text { when } \lim _{q \rightarrow \infty}=[0]_{n \times n}
\end{aligned}
$$

Step 6: Obtaining INRM.

To obtain the INRM, the Equations (7) and (8) are used to calculate the total influence relation matrix $T$. Each of row sum and column sum can be calculated in the matrix $T$.

$$
\begin{gathered}
O=\left(O_{i}\right)_{n \times 1}=\left[\sum_{j=1}^{n} t_{i j}\right]_{n \times 1}=\left(O_{1}, \ldots, O_{i}, \ldots, O_{n}\right) \\
r=\left(r_{i}\right)_{n \times 1}=\left(r_{j}\right)_{n \times 1}^{\prime}=\left[\sum_{j=1}^{n} t_{i j}\right]_{n \times 1}^{\prime}=\left(r_{1}, \ldots, r_{i}, \ldots, r_{n}\right)
\end{gathered}
$$


In the total influence relation matrix $T, O_{i}$ is the sum of a row and represents the total effects (both direct and indirect) of criterion/perspective $i$ on all other criteria/perspectives $\left[\sum_{j=1}^{n} t_{i j}\right]_{n \times 1}$. On the other hand, $r_{j}$ is the column sum in the matrix $T$ and represents the total effects (both direct and indirect) of criterion/perspective $j$ received from all other criteria/perspectives $\left[\sum_{j=1}^{n} t_{i j}\right]_{n \times 1}^{\prime}\left(O_{i}+r_{i}\right)$ represents the strength of the total influences (both giving and received), indicating the degree of importance of the criterion/perspective $i$ in the system. $\left(O_{i}+r_{i}\right)$ indicates the degree of the cause of the total influence. If $\left(O_{i}+r_{i}\right)$ is positive, it means that criterion/perspective $i$ is a causer. If $\left(O_{i}+r_{i}\right)$ is negative, it means that criterion $i$ is a receiver.

Step 7: Constructing the total influence relation matrix of criteria $T_{C}$ and dimensions $T_{D}$.

To calculate the total influence relation matrix of criteria, the matrix $T_{C}$ is defined and shown in Equation (9), where $\sum_{j=1}^{m} m_{j}=n, m<n$, and $T_{C}^{i j}$ as an $m_{i} \times m_{j}$ matrix:

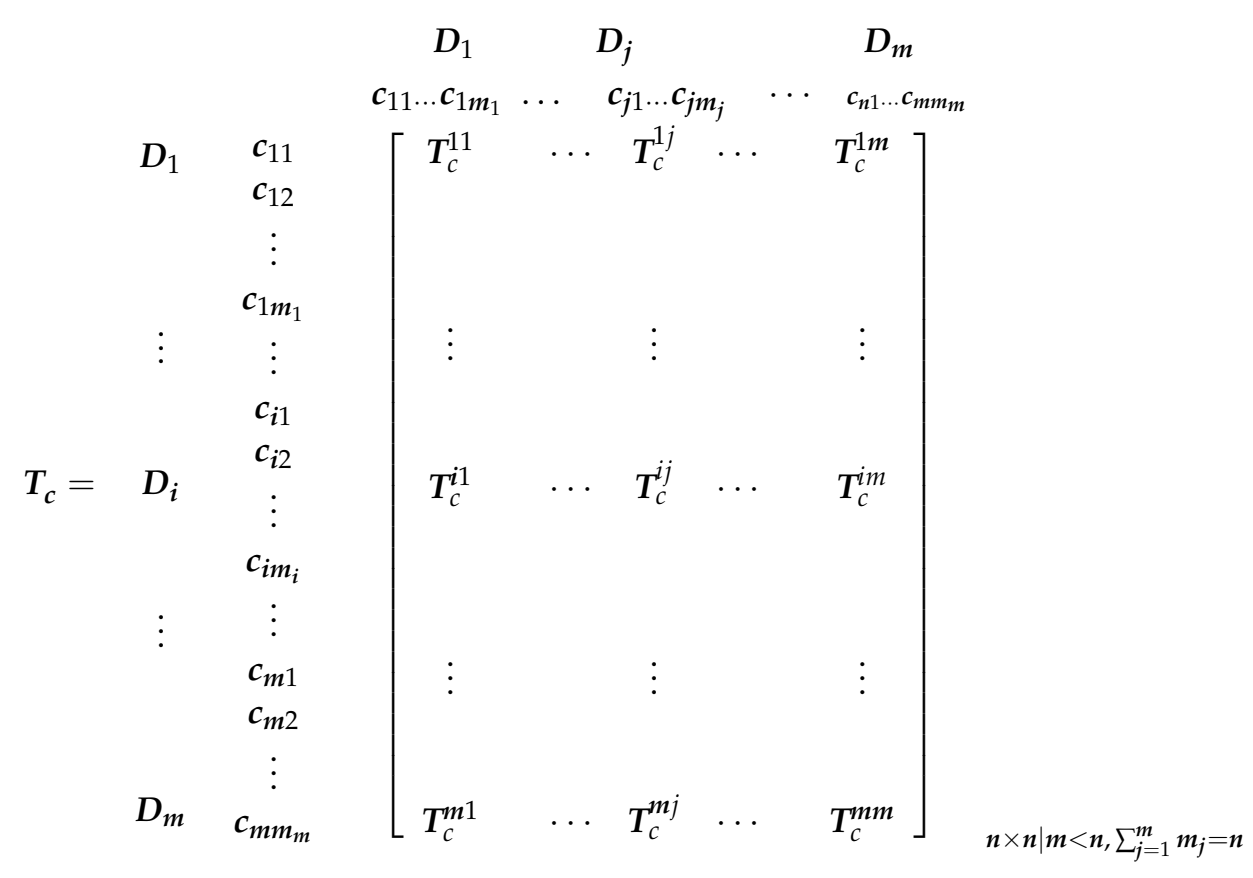

where $D_{m}$ is the $m$ th cluster; $C_{m m}$ is the $m$ th criterion in the $m$ th dimension. $T_{C}^{i j}$ is a submatrix of the influence relation for the criteria. The influence is originated from a comparison of the $i$ th dimension with the $j$ th dimension. If the $i$ th dimension has no influence on the $j$ th dimension, the matrix is submatrix $T_{C}^{i j}=[0]$. It demonstrates that the independence (e.g., there is no influence relation) of each criterion on other criteria. The total influence relation matrix of dimension $T_{D}$ is shown in Equation (10):

$$
T_{D}=\left[\begin{array}{ccccc}
t_{11} & \ldots & t_{1 j} & \ldots & t_{1 m} \\
\vdots & & \vdots & & \vdots \\
t_{i 1} & \ldots & t_{i j} & \ldots & t_{i m} \\
\vdots & & \vdots & & \vdots \\
d_{m 1} & \ldots & t_{m j} & \ldots & t_{m m}
\end{array}\right]_{m \times m}
$$




\subsubsection{The Second Phase: DANP by Combing DEMATEL and ANP}

To conduct the relation matrix of the total influence from the first step into the influential weights (IWs) or global weights of the criteria (vector), the ANP is hereby used in DEMATEL process. IWs were obtained by multiplying the weighted supermatrix $W^{\alpha}$ itself until convergence emerged. The purpose was to distinguish the priority order on the basis of influence degree for VIKOR calculations. The calculation steps are presented below.

Step 1: Calculating the unweighted supermatrix $W^{\alpha}$.

First is to normalize the total influence relation matrix $T_{C}$ by dimensions. It is shown in Equation (11):

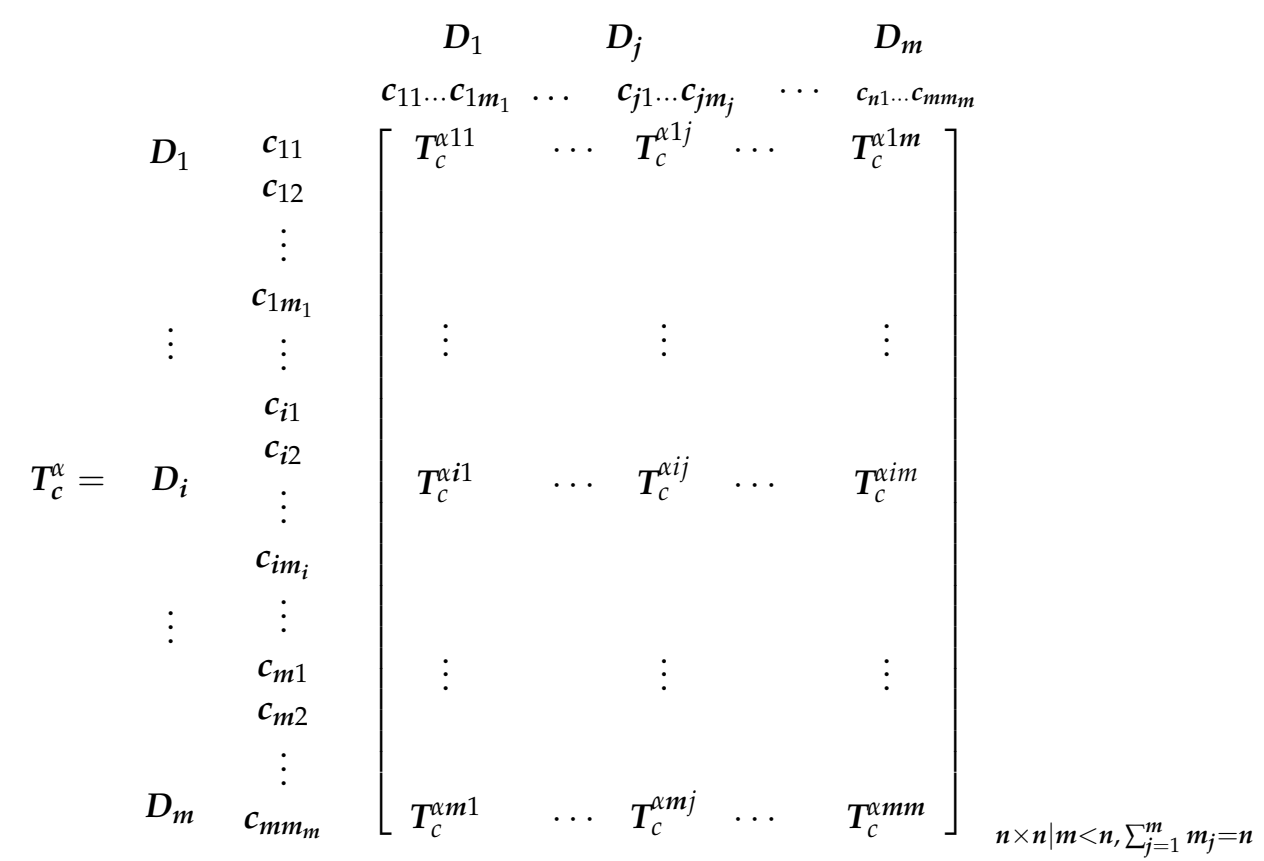

denotes the normalized total influence relation matrix of criteria by dimensions. $T_{C}^{\alpha 14}$ It is derived from Equations (12) and (13). Then, $T_{C}^{\alpha m m}$ can be obtained.

$$
t_{i}^{14}=\sum_{j=1}^{m 4} t_{i j}^{14}
$$

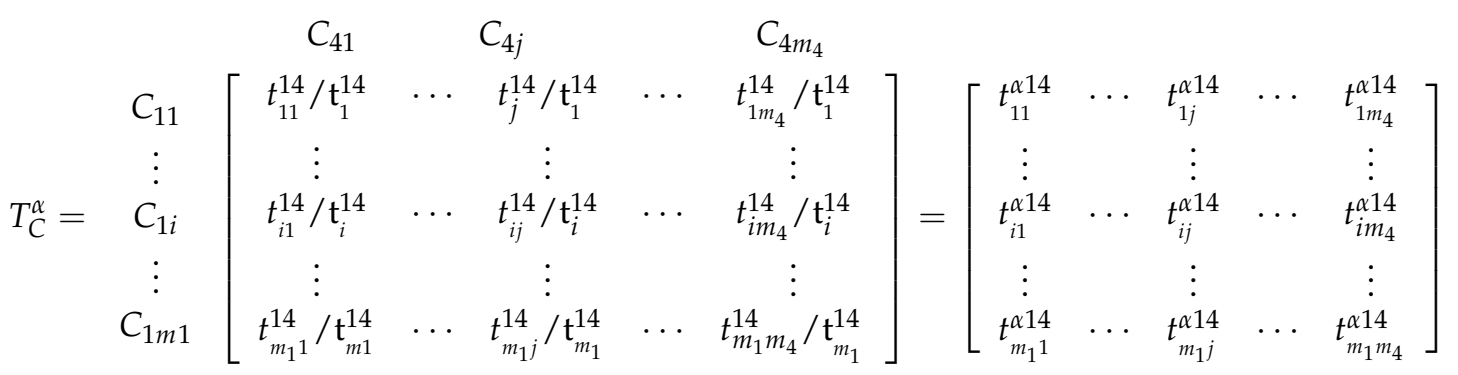

The unweighted supermatrix $W^{\alpha}$ can be calculated by transposing the normalized influence relation matrix $T_{C}^{\alpha}$ by dimensions. This is based on the pairwise comparisons of the criteria, applying the ANP concept. So, $W^{\alpha}=\left(T_{C}^{\alpha}\right)^{\prime}$ is defined in Equation (14): 


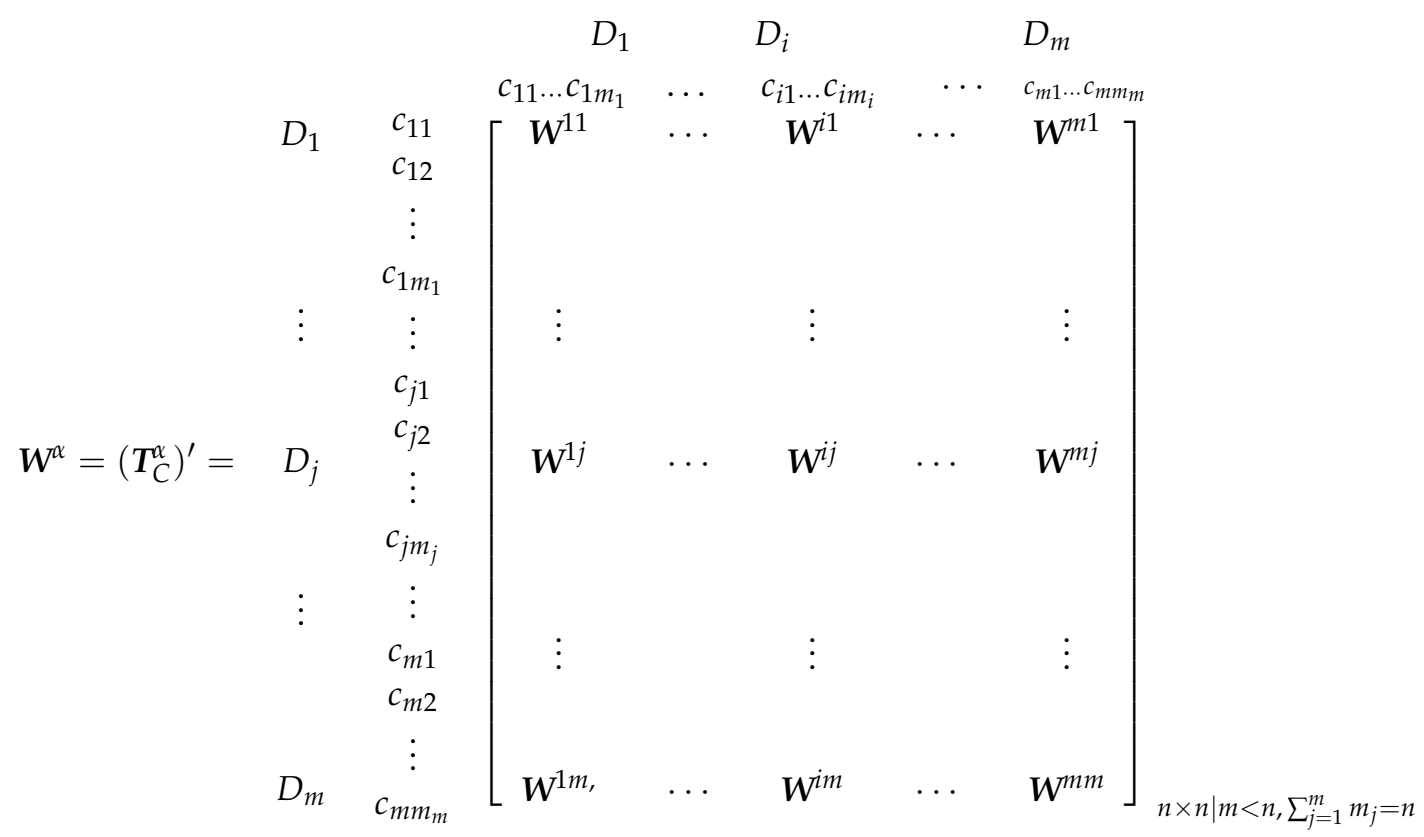

Step 2: Calculating weighted supermatrix.

Using the total influence-relation matrix, $T_{D}$ divided by $i=\sum_{j=1}^{m} t_{i j}, i=1,2, \ldots, m$, the normalized total influence-relation matrix of dimensions can be calculated. It is shown in Equation (15):

$$
T_{D}^{\alpha}=\left[\begin{array}{ccccc}
t_{11} / d_{1} & \ldots & t_{1 j} / d_{1} & \ldots & t_{1 m} / d_{1} \\
\vdots & & \vdots & & \vdots \\
t_{i 1} / d_{i} & \ldots & t_{i j} / d_{i} & \ldots & t_{i m} / d_{i} \\
\vdots & & \vdots & & \vdots \\
t_{m 1} / d_{m} & \ldots & t_{m j} / d_{m} & \ldots & t_{m m} / d_{m}
\end{array}\right]_{m \times m}=\left[\begin{array}{ccccc}
t_{11}^{\alpha D} & \ldots & t_{1 j}^{\alpha D} & \ldots & t_{1 m}^{\alpha D} \\
\vdots & & \vdots & & \vdots \\
t_{i 1}^{\alpha D} & \ldots & t_{i j}^{\alpha D} & \ldots & t_{i m}^{\alpha D} \\
\vdots & & \vdots & \\
t_{m 1}^{\alpha D} & \ldots & t_{m j}^{\alpha D} & \ldots & t_{m m}^{\alpha D}
\end{array}\right]_{m \times m}
$$

Then, three matrices, including $T_{D}^{\alpha}$, the unweighted supermatrix $W^{\alpha}$, and the weighted supermatrix $W$, can be calculated using Equation (16). $t_{i j}^{\alpha D}$ is a scalar. $\sum_{j=1}^{m} m_{j}=n$

$$
\begin{array}{ccc}
D_{1} & D_{i} & D_{m}
\end{array}
$$

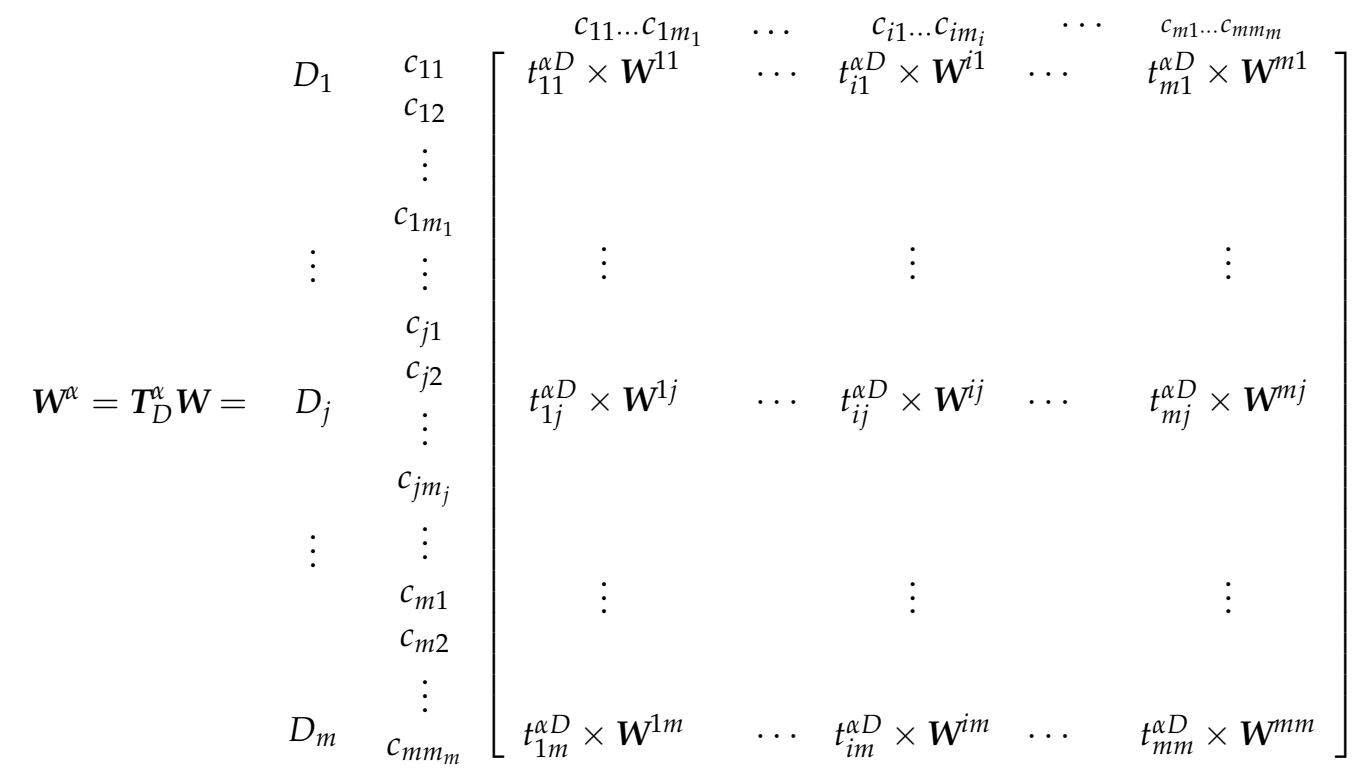

Step 3: Limiting weighted supermatrix. 
To limit the weighted supermatrix, it can be done by raising supermatrix to the $z$ th power until it has converged and become a stable supermatrix. The global priority vectors, global weight $W^{g}$, the IWs of DANP, are obtained. It is $\lim _{z \rightarrow \infty}(W)^{z}$, where $z$ represents any number of power. By summing the IWs of each criterion in every dimension, the local weight of dimension $W_{D}^{l}$ can be obtained. Subsequently, the global weight of each criterion can be divided by the local weight of its own dimension to yield the local weight of criteria $W_{c}^{l}$.

\subsubsection{The Third Phase: Modified VIKOR}

The VIKOR was modified here against the traditional form using the two calculation steps below.

Step 1: Setting the ideal levels and the worst value to fit the current real-world situation.

Both traditional and modified VIKOR are started to define the best value (ideal level) shown as $f_{j}^{a s p i r e d}$ in $\mathrm{j}$ criterion and the worst value $f_{j}^{\text {worst }}$ for all criteria.

1. Traditional VIKOR

The positive ideal solution: $f^{*}=\left(f_{1}^{*}, \ldots, f_{j}^{*}, \ldots, f_{n}^{*}\right)$ where $f_{j}^{*}=\max _{k}\left\{f_{k j} \mid k=1,2, \ldots, b\right\}$;

The negative ideal solution: $f^{-}=\left(f_{1}^{-}, \ldots, f_{j}^{-}, \ldots, f_{n}^{-}\right)$where $f_{j}^{-}=\min _{k}\left\{f_{k j} \mid k=1,2, \ldots, b\right\}$

This traditional form can only be used for the ranking and selecting alternatives (more than two alternatives) $f_{j}^{-}=\min _{k} f_{k j}$ and $f_{j}^{-}=\min _{k} f_{k j}$ when $k=1,2, \ldots, b$.

2. The modified form

The $\left.\begin{array}{l}\text { ideal } \\ f_{j}^{\text {woorst }}=0\left(f_{1}^{a s p i r e d}, \ldots, f_{j}^{a s p i r e d}, \ldots, f_{n}^{a s p i r e d}\right.\end{array}\right)$
$S_{k}=\sum_{j=1}^{n} w_{j} r_{k j}=\sum_{j=1}^{n} w_{j}\left(\left|f_{j}^{\text {aspired }}-f_{k j}\right|\right) /\left(\left|f_{j}^{\text {aspired }}-f_{j}^{\text {woorst }}\right|\right)$ or the best value.

The worst value is defined as: $f^{\text {worst }}=\left(f_{1}^{\text {worst }}, \ldots, f_{j}^{\text {worst }}, \ldots, f_{n}^{\text {worst }}\right)$, where $f_{j}^{\text {worst }}$ is the worst value.

In this study, performance scores ranging from 0 to 10 (very disagree $\leftarrow 0,1,2, \ldots, 9$, $10 \rightarrow$ very agree) are used using natural language in the linguistic/semantic questionnaire. Hence, $f_{j}^{\text {aspired }}=10$ is defined as the ideal level, and $f_{j}^{\text {worst }}=0$ as the worst value. It is meant to avoid choosing the best among inferiors.

Step 2: Determining the mean group utility for the gap.

These values can be calculated using Equation (17). Until then, we can establish the priority improvement strategy.

$$
S_{k}=\sum_{j=1}^{n} w_{j} r_{k j}=\sum_{j=1}^{n} w_{j}\left(\left|f_{j}^{\text {aspired }}-f_{k j}\right|\right) /\left(\left|f_{j}^{\text {aspired }}-f_{j}^{\text {worst }}\right|\right)
$$

Here, $S_{k}$ is defined as the normalized ratio (\%) of distance to the ideal level. It represents the synthesized gaps of the criteria. $w_{j}$ is the IWs of the criteria, which is obtained by DANP in the second phase.

\section{Empirical Case of Taiwanese Tourism Crisis Measures for Travel Agencies \\ 4.1. Research Problem}

Historically (e.g., SARS, 2003; global financial crisis, 2009), medium and small size businesses are particularly vulnerable to the impact of crises because they have limited capacities for risk reduction [12]. This is particularly true for Taiwanese travel agencies. 
Over $90 \%$ of them are small-scale companies [55]. The Taiwanese authority has thus urged staff collaboration with enterprises and the government's plan for recovery and continuity. As stated by government guidelines [11], a host organization can arrange training courses such as those of this study (Table 1), developed by some Travel Agency Association in Taiwan. The agents were recruited to attend the training. They were paid NTD 158 per $h$ for a maximum of $120 \mathrm{~h}$ per month. The total amount is transferred to each company as a paycheck subsidy. Such paid training is expected to proceed for six months, from April to September 2020, according to the policy.

The questions that were raised are as follows:

(1) What is the effectiveness of this paid training?

(2) What are the interrelations between policy object, courses, and adaptation behavior?

(3) What/how can the effectiveness of the measure be improved to reach the optimal level? It is ultimately expected that the empirical results will provide an innovative approach for crisis management with valuable learning outcomes (learning readiness) $[5,6]$.

\subsection{Results and Discussion}

\subsubsection{INRM of Paid Training Measures by DEMATEL}

The influence dimensions and criteria were calculated by the DEMATEL method (Tables 2-5). The results were also illustrated in an INRM (Figure 2). The INRM demonstrates the interaction network relations among criteria regarding this paid training of travel agents. The improvement priorities can thus be produced from the perspectives of dimensions or criteria and indexed.

$$
\frac{1}{n(n-1)} \sum_{i=1}^{n} \sum_{j=1}^{n}\left(\left|d_{i j}^{H}-d_{i j}^{H-1}\right| / d_{i j}^{H}\right) \times \mathbf{1 0 0} \%, 3.4 \%<5 \%,
$$

where $d_{i j}^{H}$ and $d_{i j}^{H-1}$ denotes the average scores of the $\mathrm{H}$ experts to $j$ by $H=20$ (experts); $n=10$ denotes the numbers of criteria.

Table 2. Initial influence matrix $D$.

\begin{tabular}{ccccccccccc}
\hline $\mathrm{D}$ & $\mathrm{C}_{\mathbf{1 1}}$ & $\mathrm{C}_{\mathbf{1 2}}$ & $\mathrm{C}_{\mathbf{1 3}}$ & $\mathrm{C}_{\mathbf{1 4}}$ & $\mathrm{C}_{\mathbf{2 1}}$ & $\mathrm{C}_{\mathbf{2 2}}$ & $\mathrm{C}_{\mathbf{2 3}}$ & $\mathrm{C}_{\mathbf{3 1}}$ & $\mathrm{C}_{\mathbf{3 2}}$ & $\mathrm{C}_{\mathbf{3 3}}$ \\
\hline $\boldsymbol{C}_{\mathbf{1 1}}$ & 0.00 & 3.17 & 3.33 & 2.92 & 2.92 & 3.00 & 2.42 & 2.25 & 3.17 & 1.83 \\
$\boldsymbol{C}_{\mathbf{1 2}}$ & 2.58 & 0.00 & 3.75 & 3.25 & 3.25 & 3.50 & 3.00 & 2.42 & 3.42 & 1.75 \\
$\boldsymbol{C}_{13}$ & 3.08 & 3.75 & 0.00 & 3.08 & 2.92 & 3.25 & 3.25 & 2.42 & 3.33 & 1.58 \\
$\boldsymbol{C}_{\mathbf{1 4}}$ & 2.17 & 2.83 & 3.25 & 0.00 & 2.58 & 3.33 & 2.67 & 2.42 & 3.33 & 1.67 \\
$\boldsymbol{C}_{21}$ & 2.58 & 3.33 & 3.08 & 2.75 & 0.00 & 3.25 & 3.17 & 2.08 & 3.08 & 1.42 \\
$\boldsymbol{C}_{22}$ & 2.25 & 3.58 & 3.25 & 3.08 & 3.00 & 0.00 & 3.17 & 2.50 & 3.42 & 1.42 \\
$\boldsymbol{C}_{23}$ & 2.08 & 2.75 & 2.83 & 2.33 & 3.00 & 2.92 & 0.00 & 2.42 & 2.83 & 1.42 \\
$\boldsymbol{C}_{31}$ & 2.50 & 2.42 & 2.75 & 2.42 & 2.33 & 2.58 & 2.33 & 0.00 & 2.42 & 1.08 \\
$\boldsymbol{C}_{32}$ & 2.75 & 3.25 & 3.33 & 3.08 & 2.58 & 3.17 & 2.75 & 2.00 & 0.00 & 1.33 \\
$C_{33}$ & 1.58 & 1.75 & 1.50 & 1.42 & 1.33 & 1.83 & 1.17 & 1.25 & 1.33 & 0.00 \\
\hline
\end{tabular}

Table 3. Normalized average direct influence relation matrix $N$.

\begin{tabular}{ccccccccccc}
\hline $\mathbf{D}$ & $\mathbf{C}_{\mathbf{1 1}}$ & $\mathbf{C}_{\mathbf{1 2}}$ & $\mathrm{C}_{\mathbf{1 3}}$ & $\mathbf{C}_{\mathbf{1 4}}$ & $\mathbf{C}_{\mathbf{2 1}}$ & $\mathbf{C}_{\mathbf{2 2}}$ & $\mathrm{C}_{\mathbf{2 3}}$ & $\mathrm{C}_{\mathbf{3 1}}$ & $\mathrm{C}_{\mathbf{3 2}}$ & $\mathrm{C}_{\mathbf{3 3}}$ \\
\hline$C_{11}$ & 0.00 & 0.12 & 0.12 & 0.11 & 0.11 & 0.11 & 0.09 & 0.08 & 0.12 & 0.07 \\
$C_{12}$ & 0.10 & 0.00 & 0.14 & 0.12 & 0.12 & 0.13 & 0.11 & 0.09 & 0.13 & 0.06 \\
$C_{13}$ & 0.11 & 0.14 & 0.00 & 0.11 & 0.11 & 0.12 & 0.12 & 0.09 & 0.12 & 0.06 \\
$C_{14}$ & 0.08 & 0.10 & 0.12 & 0.00 & 0.10 & 0.12 & 0.10 & 0.09 & 0.12 & 0.06 \\
$C_{21}$ & 0.10 & 0.12 & 0.11 & 0.10 & 0.00 & 0.12 & 0.12 & 0.08 & 0.11 & 0.05 \\
$C_{22}$ & 0.08 & 0.13 & 0.12 & 0.11 & 0.11 & 0.00 & 0.12 & 0.09 & 0.13 & 0.05 \\
$C_{23}$ & 0.08 & 0.10 & 0.10 & 0.09 & 0.11 & 0.11 & 0.00 & 0.09 & 0.10 & 0.05 \\
$C_{31}$ & 0.09 & 0.09 & 0.10 & 0.09 & 0.09 & 0.10 & 0.09 & 0.00 & 0.09 & 0.04 \\
$C_{32}$ & 0.10 & 0.12 & 0.12 & 0.11 & 0.10 & 0.12 & 0.10 & 0.07 & 0.00 & 0.05 \\
$C_{33}$ & 0.06 & 0.06 & 0.06 & 0.05 & 0.05 & 0.07 & 0.04 & 0.05 & 0.05 & 0.00 \\
\hline
\end{tabular}


Table 4. Total influence matrix of criteria $T_{C}$.

\begin{tabular}{ccccccccccc}
\hline $\mathrm{D}$ & $\mathrm{C}_{\mathbf{1 1}}$ & $\mathrm{C}_{\mathbf{1 2}}$ & $\mathrm{C}_{\mathbf{1 3}}$ & $\mathrm{C}_{\mathbf{1 4}}$ & $\mathrm{C}_{\mathbf{2 1}}$ & $\mathrm{C}_{\mathbf{2 2}}$ & $\mathrm{C}_{\mathbf{2 3}}$ & $\mathrm{C}_{\mathbf{3 1}}$ & $\mathrm{C}_{\mathbf{3 2}}$ & $\mathrm{C}_{\mathbf{3 3}}$ \\
\hline $\boldsymbol{C}_{\mathbf{1 1}}$ & 0.67 & 0.92 & 0.94 & 0.85 & 0.84 & 0.92 & 0.83 & 0.69 & 0.91 & 0.49 \\
$\boldsymbol{C}_{\mathbf{1 2}}$ & 0.80 & 0.88 & 1.01 & 0.91 & 0.90 & 0.99 & 0.90 & 0.74 & 0.98 & 0.51 \\
$\boldsymbol{C}_{\mathbf{1 3}}$ & 0.81 & 0.99 & 0.88 & 0.90 & 0.88 & 0.98 & 0.90 & 0.74 & 0.97 & 0.51 \\
$\boldsymbol{C}_{\mathbf{1 4}}$ & 0.72 & 0.89 & 0.91 & 0.73 & 0.81 & 0.90 & 0.81 & 0.68 & 0.90 & 0.47 \\
$\boldsymbol{C}_{\mathbf{2 1}}$ & 0.75 & 0.93 & 0.93 & 0.84 & 0.74 & 0.92 & 0.85 & 0.69 & 0.91 & 0.47 \\
$\boldsymbol{C}_{\mathbf{2 2}}$ & 0.76 & 0.96 & 0.96 & 0.88 & 0.86 & 0.84 & 0.87 & 0.72 & 0.95 & 0.49 \\
$\boldsymbol{C}_{\mathbf{2 3}}$ & 0.68 & 0.84 & 0.85 & 0.76 & 0.77 & 0.84 & 0.68 & 0.64 & 0.83 & 0.44 \\
$\boldsymbol{C}_{\mathbf{3 1}}$ & 0.65 & 0.78 & 0.79 & 0.72 & 0.71 & 0.78 & 0.71 & 0.52 & 0.77 & 0.40 \\
$\boldsymbol{C}_{\mathbf{3 2}}$ & 0.75 & 0.91 & 0.92 & 0.84 & 0.81 & 0.91 & 0.82 & 0.67 & 0.79 & 0.46 \\
$\boldsymbol{C}_{\mathbf{3 3}}$ & 0.42 & 0.50 & 0.50 & 0.46 & 0.45 & 0.51 & 0.44 & 0.38 & 0.49 & 0.23 \\
\hline
\end{tabular}

Table 5. Total influence matrix of dimensions $T_{D}$.

\begin{tabular}{cccc}
\hline $\mathbf{T}_{\mathbf{D}}$ & $\mathbf{D}_{\mathbf{1}}$ & $\mathbf{D}_{\mathbf{2}}$ & $\mathbf{D}_{\mathbf{3}}$ \\
\hline $\mathbf{D}_{\mathbf{1}}$ & 0.86 & 0.89 & 0.72 \\
$\mathbf{D}_{\mathbf{2}}$ & 0.84 & 0.82 & 0.68 \\
$\mathbf{D}_{\mathbf{3}}$ & 0.69 & 0.68 & 0.52 \\
\hline
\end{tabular}

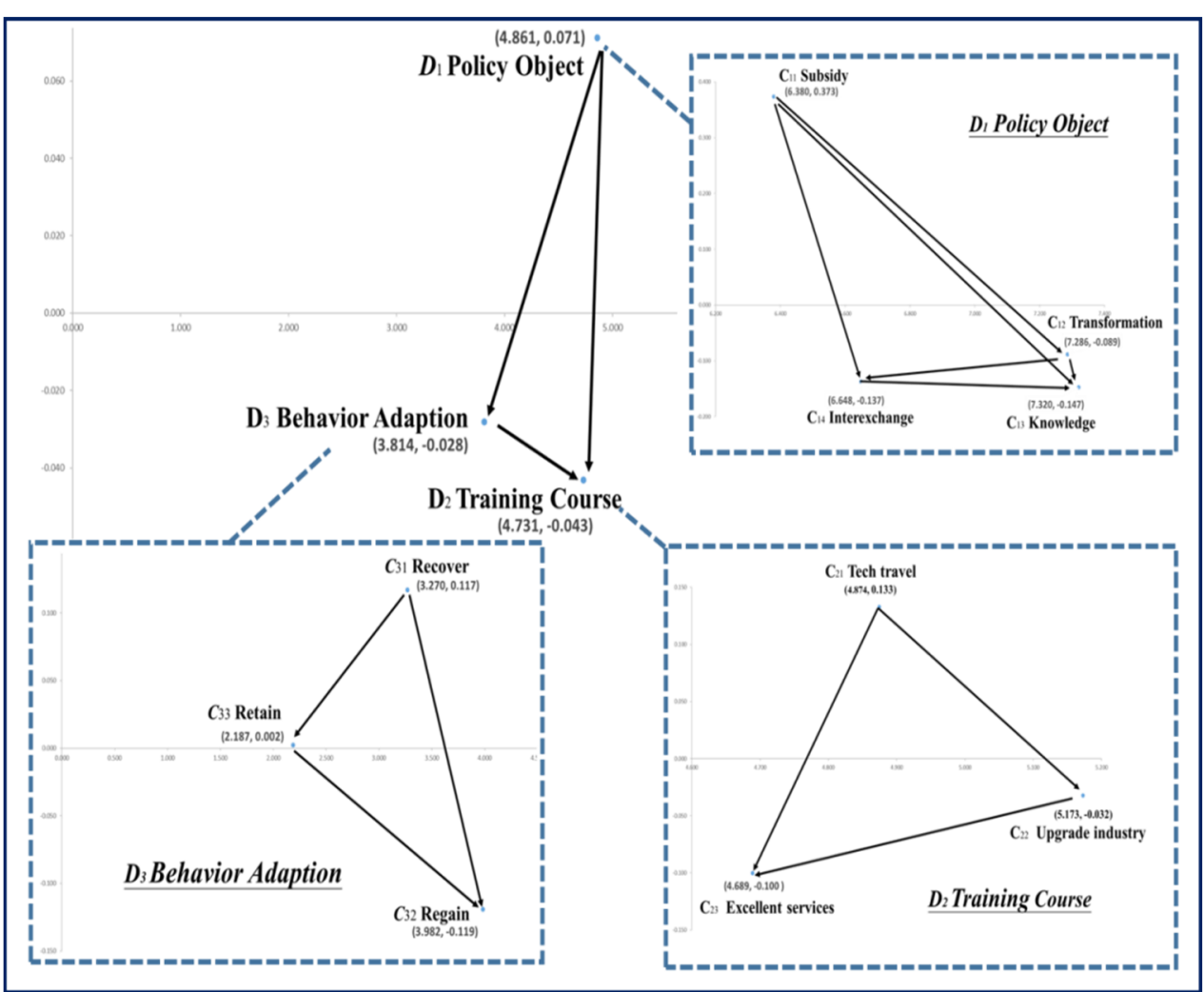

Figure 2. INRM (influential network relation map) of paid training measure. 
From the perspective of dimensions, D1-Policy object exerts influence on D3-Adaption behavior and D2-Training courses, indicating that most influential dimension is D1-Policy object. In contrast, the most influenced one is D1-Training courses. Using the network influencing effects of D1-Policy object can directly improve the other two dimensions and double up the efficiency of measure. Therefore, the improvement priority is sequenced as: D1-D3-D2.

Such influencing network effects can be also observed among the criteria. For instance, in D1-Policy object, according to INRM, the order could be sequenced as C11-Subsidy, C12-Transformation, C14-Interexchange, and C13-Knowledge. Similarly, in D2-Training courses, the influencing network effects could be ordered as C21-Tech travel, C22-Upgrade industry, and C23-Excellent services. Then, in D3-Behavior adaption, the order could be sequenced as C31-Recovery, C33-Retain, and C32-Regain. These orders indicate the improvement priority.

\subsubsection{Gaps of Paid Training Measures by Modified VIKOR}

In this research, the modified VIKOR's gap values were calculated more efficiently using the weights by DANP (Tables 6 and 7). These gap/performance values show the general achievable degree to the ideal level of the paid training measure (Table 8). Overall, the mean of performance score is 6.303 (to 10). The mean of the gap to ideal level is 0.370 (to 0 ). This result indicates that, overall, the trainees have a moderate satisfaction to the measure. It also reveals the improvement priorities according to gap/performance values of dimensions or criteria, which is indexed in Table 9.

Table 6. Weighted supermatrix $W$.

\begin{tabular}{ccccccccccc}
\hline $\mathbf{W}$ & $\mathbf{C}_{\mathbf{1 1}}$ & $\mathbf{C}_{\mathbf{1 2}}$ & $\mathbf{C}_{\mathbf{1 3}}$ & $\mathbf{C}_{\mathbf{1 4}}$ & $\mathbf{C}_{\mathbf{2 1}}$ & $\mathbf{C}_{\mathbf{2 2}}$ & $\mathbf{C}_{\mathbf{2 3}}$ & $\mathbf{C}_{\mathbf{3 1}}$ & $\mathbf{C}_{\mathbf{3 2}}$ & $\mathbf{C}_{\mathbf{3 3}}$ \\
\hline$C_{11}$ & 0.07 & 0.08 & 0.08 & 0.08 & 0.08 & 0.08 & 0.08 & 0.08 & 0.08 & 0.08 \\
$C_{12}$ & 0.10 & 0.09 & 0.10 & 0.10 & 0.10 & 0.10 & 0.10 & 0.10 & 0.10 & 0.10 \\
$C_{13}$ & 0.10 & 0.10 & 0.09 & 0.10 & 0.10 & 0.10 & 0.10 & 0.10 & 0.10 & 0.10 \\
$C_{14}$ & 0.09 & 0.09 & 0.09 & 0.08 & 0.09 & 0.09 & 0.09 & 0.09 & 0.09 & 0.09 \\
$C_{21}$ & 0.12 & 0.12 & 0.12 & 0.11 & 0.10 & 0.12 & 0.12 & 0.12 & 0.12 & 0.12 \\
$C_{22}$ & 0.13 & 0.13 & 0.13 & 0.13 & 0.13 & 0.11 & 0.13 & 0.13 & 0.13 & 0.13 \\
$C_{23}$ & 0.12 & 0.12 & 0.12 & 0.12 & 0.12 & 0.12 & 0.10 & 0.12 & 0.12 & 0.11 \\
$C_{31}$ & 0.10 & 0.10 & 0.10 & 0.10 & 0.10 & 0.10 & 0.10 & 0.09 & 0.10 & 0.10 \\
$C_{32}$ & 0.13 & 0.13 & 0.13 & 0.13 & 0.13 & 0.13 & 0.13 & 0.13 & 0.11 & 0.12 \\
$C_{33}$ & 0.07 & 0.07 & 0.07 & 0.07 & 0.07 & 0.07 & 0.07 & 0.07 & 0.07 & 0.06 \\
\hline
\end{tabular}

Table 7. Weighted supermatrix $W^{\alpha}$.

\begin{tabular}{ccccccccccc}
\hline $\boldsymbol{W}^{\boldsymbol{\alpha}}$ & $\mathbf{C}_{\mathbf{1 1}}$ & $\mathbf{C}_{\mathbf{1 2}}$ & $\mathbf{C}_{\mathbf{1 3}}$ & $\mathbf{C}_{\mathbf{1 4}}$ & $\mathbf{C}_{\mathbf{2 1}}$ & $\mathbf{C}_{\mathbf{2 2}}$ & $\mathbf{C}_{\mathbf{2 3}}$ & $\mathbf{C}_{\mathbf{3 1}}$ & $\mathbf{C}_{\mathbf{3 2}}$ & $\mathbf{C}_{\mathbf{3 3}}$ \\
\hline$C_{11}$ & 0.078 & 0.078 & 0.078 & 0.078 & 0.078 & 0.078 & 0.078 & 0.078 & 0.078 & 0.078 \\
$C_{12}$ & 0.096 & 0.096 & 0.096 & 0.096 & 0.096 & 0.096 & 0.096 & 0.096 & 0.096 & 0.096 \\
$C_{13}$ & 0.096 & 0.096 & 0.096 & 0.096 & 0.096 & 0.096 & 0.096 & 0.096 & 0.096 & 0.096 \\
$C_{14}$ & 0.088 & 0.088 & 0.088 & 0.088 & 0.088 & 0.088 & 0.088 & 0.088 & 0.088 & 0.088 \\
$C_{21}$ & 0.115 & 0.115 & 0.115 & 0.115 & 0.115 & 0.115 & 0.115 & 0.115 & 0.115 & 0.115 \\
$C_{22}$ & 0.126 & 0.126 & 0.126 & 0.126 & 0.126 & 0.126 & 0.126 & 0.126 & 0.126 & 0.126 \\
$C_{23}$ & 0.115 & 0.115 & 0.115 & 0.115 & 0.115 & 0.115 & 0.115 & 0.115 & 0.115 & 0.115 \\
$C_{31}$ & 0.096 & 0.096 & 0.096 & 0.096 & 0.096 & 0.096 & 0.096 & 0.096 & 0.096 & 0.096 \\
$C_{32}$ & 0.125 & 0.125 & 0.125 & 0.125 & 0.125 & 0.125 & 0.125 & 0.125 & 0.125 & 0.125 \\
$C_{33}$ & 0.066 & 0.066 & 0.066 & 0.066 & 0.066 & 0.066 & 0.066 & 0.066 & 0.066 & 0.066 \\
\hline
\end{tabular}


Table 8. The performance evaluation of the case study using the modified VIKOR.

\begin{tabular}{ccccc}
\hline Dimensions/Criteria & Local Weight & Global Weight & Performance & Gap \\
\hline $\mathrm{D}_{1}$ Policy object & 0.357 & & 6.609 & 0.339 \\
$\mathrm{C}_{11}$ Subsidy & 0.218 & 0.078 & 7.000 & 0.300 \\
$\mathrm{C}_{12}$ Transformation & 0.267 & 0.096 & 6.333 & 0.367 \\
$\mathrm{C}_{13}$ Knowledge & 0.270 & 0.096 & 6.667 & 0.333 \\
$\mathrm{C}_{14}$ Interexchange & 0.245 & 0.088 & 6.500 & 0.350 \\
$\mathrm{D}_{2}$ Training courses & 0.356 & & 6.944 & 0.306 \\
$\mathrm{C}_{21}$ Tech travel & 0.322 & 0.115 & 6.667 & 0.333 \\
$\mathrm{C}_{22}$ Upgrade industry & 0.355 & 0.126 & 6.917 & 0.308 \\
$\mathrm{C}_{23}$ Excellent services & 0.323 & 0.115 & 7.250 & 0.275 \\
$\mathrm{D}_{3}$ Behavior adaption & 0.287 & & 5.126 & 0.487 \\
C 31 Recover & 0.334 & 0.096 & 5.083 & 0.492 \\
$\mathrm{C}_{32}$ Regain & 0.437 & 0.125 & 5.750 & 0.425 \\
$\mathrm{C}_{33}$ Retain & 0.230 & 0.066 & 4.000 & 0.600 \\
\hline Total performance & & & 6.303 & \\
Total Gap & & & & 0.370 \\
\hline
\end{tabular}

Table 9. Action plan for improving paid training tourism crisis measures.

\begin{tabular}{|c|c|c|c|}
\hline & Method (Effect/Benchmark) & Perspective & Improving Sequence \\
\hline \multirow[b]{2}{*}{ Plan 1} & \multirow{2}{*}{$\begin{array}{l}\text { INRM } \\
\text { (network relational influence effect, } \\
\text { from the most influencing to the } \\
\text { most influenced) }\end{array}$} & Dimension & D1-D3-D2 \\
\hline & & Criteria & $\begin{array}{c}\text { D1: } C_{11}-C_{12}-C_{14}-C_{13} \\
\text { D2: } C_{21}-C_{22}-C_{23} \\
\text { D3: } C_{31}-C_{33}-C_{32}\end{array}$ \\
\hline \multirow[b]{2}{*}{ Plan 2} & \multirow[b]{2}{*}{$\begin{array}{l}\text { Gap (distance to aspiration level, } \\
\text { from the smallest to the largest) }\end{array}$} & Dimension & D2-D1-D3 \\
\hline & & Criteria & $\begin{array}{c}\text { D1: } C_{11}-C_{13}-C_{14}-C_{12} \\
\text { D2: } C_{23}-C_{22}-C_{21} \\
\text { D3: } C_{32}-C_{31}-C_{33}\end{array}$ \\
\hline
\end{tabular}

Concerning the overall performance of dimensions, D2-Training courses had the smallest gap value, followed by D1-policy object and D3-behavior adaption. In order to efficiently reach the aspiration level, the achievement priority should be sequenced as D2-D1-D3. In this case, to improve the training courses to meet expectations is the first priority.

Regarding the overall performance of the criteria, C23-excellent services received the smallest gap, followed by C11-subsidy, C13-knowledge, and C21-tech travel. This indicated that learning in "excellent services" is the most achievable criterion among all criteria.

In the individual dimension, the result also demonstrates the priorities of improvement strategies. For instance, in D1-Policy object, "C11-Subsidies" emerges as the most achievable one with the smallest gap, followed by C12-knowledge. So, the achievable order can be sequenced as C11-C13-C14-C12. Similarly, in D2-Training courses, the priority can be ordered as: C23-C22-C21.

Notably, larger gaps were found in D3-Behavioral adaptation, C33-Retain received the largest gap value (0.600), followed by C31-Recover (0.4250) and C32-Regain (0.492), indicating that these were the most unachievable criteria in terms of the behavior adaption of an individual. Currently, most of these trainees are stranded in the crisis.

\subsection{Implications}

There are many facilitated tourism policies, but few physical evaluations [14]. This case study was carried out to evaluate crisis measures responding to COVID-19 in May to September 2020. The DANP-mV model revealed implications for both academic and practical fields. 


\subsubsection{Academic Implications}

In confronting unprecedented changes in the workplace due to COVID-19, previous theories related to tourism crisis management, organizational learning, and behavior adaption were examined by our DANP-mV model. Notably, the INRM revealed that network relations exist in each of these theories/dimensions. This implies that network relations are influencing between criteria beyond linear/processional interpretation.

For instance, in the behavior adaption dimension, recover releases influence on retain and regain, and retain on regain. That is, the behavioral changes would become interrelated rather than linear, as in retain-regain-recover. It may be interpreted that the most influencing object is to reach the recover status. Due to individual differences, some trainees maybe stay in the regain status. Others may be in the retain status; however, they still try to move on to the regain status. So the "regain" emerges as the most influenced criterion (Figure 2). This interrelation expands the debate on crisis learning mechanism and process of employee resilience in the context of the workplace [67]. It may deserve to discuss for future research.

\subsubsection{Practical Implications}

The INRM (Figure 2) offers a direction for practitioners in the real world. First, D1Policy object is the most influencing dimension, and C11-Subsidy is the most influencing criterion. This meets the purpose of the current policy-to provide direct financial support for business continuity purposes as local businesses suffer from the crisis [10]. As businesses are all shut down, cash handouts may be meager but truly a blessing for agents. Moreover, influential network relations reveal policy objects influencing behavior adaption and training courses. This also consistent with the statement that policies would lead organizations or their components to adjust to changing settings by generating and adapting their routine behavior [22]. Therefore, for practitioners, the effort should be put on the policy object to double up the effectiveness of training measures. In particular, the subsidies should be the first priority because they are the most influential on the other criteria (Figure 2).

Additionally, the modified VIKOR result revealed that, overall, the gap to aspiration level was 0.370 (to 0), and performance scored 6.303 (to 10), indicating this paid training measure is just moderately agreeable. The most achievable dimension, D2-Training courses (6.944/ 0.306), could be first to improve in terms of achievement of aspiration level. C23-Excellent services can be the start-up because of its smallest gap value to reach the ideal level (Table 8). This reveals that the common need of these agents is to upgrade their capacities of excellent services. In fact, human resources are the major cost for companies [20], and majorly so for small-sized enterprise (e.g., Taiwanese travel agencies). They cannot afford the training cost either in usual times or in crisis. For practitioners, making the training courses excellent should be an urgent improvement.

D3-Behavior adaptation with larger gap values (0.487) revealed that this training measure is fairly far from the aspiring level. It should be improved to help the individuals to cope better. The start-up can be from C32-Regain (with smaller gap in this dimension). This reveals that the trainees would satisfy/expect if the training have provided them useful knowledge and skills to confront crisis. Instantly for living, subsidies may be favorable. However, in coping with both sudden and incremental changes in the workplace [20], they do need/want learning readiness to perform effective crisis management [8,23-30]. For practitioners, to adjust training contents to the real needs of employees is the first priority.

On the above basis, more improvement strategies are listed in Table 9 for particle fields. Table 9 is an evolving action plan for the current crisis measures, aiming to evolve this challenge toward continuity. It can be indexed both from the perspectives of dimensions or criteria, or by methods, INRM, or Gap. For instance, using Plan 1 (INRM), the sequence priority of dimensions to improve is D1-D3-D2. In D1, the criterion priority sequence is C11-C12-C14-C13. Similarly, using Plan 2 (Gap), the dimension priority sequence to improve is D2-D1-D3. In D1, the criterion priority sequence is C11-C13-C14-C12. 


\section{Conclusions}

For the current COVID-19 pandemic measures for travel agencies, a case study of expert Taiwanese travel agents was used to conduct the empirical test of our approach. The results demonstrated the value of the DANP-mV model in coping with complicated policy objects, learning courses, and behavior adaptions and suggested meaningful implications for future recovery efforts (Table 9). Therefore, this study is superior because it (1) established the INRM (Figure 2), which can illustrate the individual and holistic interactions beyond a linear relationship of the training measure; (2) applied the gap values to select the best strategy among the tops more precisely to improve the measure; and (3) applied Excel software, which is both simple and straight forward comparing to the traditional computation packages.

Therefore, the main contribution of this research can be (1) developing a theoretical framework addressing to learning effectiveness of crisis measures, (2) demonstrating how the DANP-mV model examines complex response and relationships between training measure variables, (3) proposing a useful improvement plan specifically for training measure of travel agents, and (4) helping to provide effective measure for travel sector to evolve the pandemic crisis.

Nevertheless, there are some limitations of this research that can be elaborated as follow. Firstly, the scaled result of this study is industry-specific and has a narrowly defined domain in the case of Taiwan. It may have a lack of generalizability for cross-industry or cross-country application. Secondly, the focus and content of the research are basically policy oriented. Yet, the levels of resilience (individual / organizational behavioral changes) and factors that influence resilience (such as social or financial capital) could be varied [20]. Future research in the field may deepen the discussion by developing a more detail multi criteria structure that is incorporated with big data.

Author Contributions: Conceptualization, C.-H.L.; methodology, C.-H.L.; software, B.L.; validation, B.L.; formal analysis, B.L.; investigation, C.-H.L.; resources, C.-H.L.; data curation, B.L.; writingoriginal draft preparation, C.-H.L.; writing—review and editing, C.-H.L.; visualization, B.L. All authors have read and agreed to the published version of the manuscript.

Funding: This research received no external funding.

Institutional Review Board Statement: Not applicable.

Informed Consent Statement: Not applicable.

Data Availability Statement: Not applicable.

Conflicts of Interest: The authors declare no conflict of interest.

\section{References}

1. World Travel \& Tourism Council. Tourism Recovery after Terrorism: How France Bounced Back. Available online: https:// medium.com/@WTTC/tourism-recovery-after-terrorism-how-france-bounced-back-ff2d25c2834a (accessed on 3 August 2020).

2. World Travel \& Tourism Council. How Do You Deal with a Crisis? Available online: https://medium.com/@WTTC/how-doyou-deal-with-a-crisis-a040bf9cddb8 (accessed on 3 August 2020).

3. World Tourism Organization (UNWTO) (Ed.) UNWTO Briefing Note-Tourism and COVID-19, Issue 1-How Are Countries Supporting Tourism Recovery? World Tourism Organization (UNWTO): Madrid, Spain, 2020. [CrossRef]

4. Lu, Y.F. The Transportation Ministry Is Criticized for Insufficient Handouts Budget for Travel Agencie. The Storm Media. Available online: https:/ / www.storm.mg/article/2381640 (accessed on 9 March 2020).

5. Kovoor-Misra, S.; Nathan, M. Timing Is Everything: The Optimal Time To Learn from Crises. J. Rev. Bus. $2000,21,31$.

6. Premeaux, S.F.; Breaux, D. Crisis Management of Human Resources: Lessons from Hurricanes Katrina and Rita. J. Hum. Resour. Plan. 2007, 30, 39.

7. Ghaderi, Z.; Mat Som, A.P.; Wang, J. Organizational Learning in Tourism Crisis Management: An Experience From Malaysia. J. Travel Tour. Mark. 2014, 31, 627-648. [CrossRef]

8. Blackman, D.; Ritchie, B.W. Tourism Crisis Management and Organizational Learning: The Role of Reflection in Developing Effective DMO Crisis Strategies. J. Travel Tour. Mark. 2008, 23, 45-57. [CrossRef]

9. Sharpley, R.; Craven, B. The 2001 Foot and Mouth Crisis-Rural Economy and Tourism Policy Implications: A Comment. Curr. Issues Tour. 2001, 4, 527-537. [CrossRef] 
10. Stafford, G.; Yu, L.; Kobina Armoo, A. Crisis Management and Recovery How Washington, D.C., Hotels Responded to Terrorism. Cornell Hotel Restaur. Adm. Q. 2002, 43, 27-40. [CrossRef]

11. Taiwan Tourism Bureau. COVID 19 Supporting Program. Available online: https://admin.taiwan.net.tw/BusinessInfo/ GuanguangTuiguang/Revitalize.htm (accessed on 3 August 2020).

12. Cushnahan, G. Crisis Management in Small-Scale Tourism. J. Travel Tour. Mark. 2004, 15, 323-338. [CrossRef]

13. Cioccio, L.; Michael, E.J. Hazard or Disaster: Tourism Management for the Inevitable in Northeast Victoria. Tour. Manag. 2007, 28, 1-11. [CrossRef]

14. Liu, C.-H.; Tzeng, G.-H.; Lee, M.-H. Improving Tourism Policy Implementation-The Use of Hybrid MCDM Models. Tour. Manag. 2012, 33, 413-426. [CrossRef]

15. Liu, C.-H. Strategies of Managing Coach Driver Job Stress for Sustainable Coach Tourism Industry-The Use of DANP-V Model. Sustainability 2020, 12, 3690. [CrossRef]

16. Qu, G.-B.; Zhao, T.-Y.; Zhu, B.-W.; Tzeng, G.-H.; Huang, S.-L. Use of a Modified DANP-MV Model to Improve Quality of Life in Rural Residents: The Empirical Case of Xingshisi Village, China. Int. J. Environ. Res. Public Health 2019, 16, 153. [CrossRef]

17. Lin, P.-J.; Shiue, Y.-C.; Tzeng, G.-H.; Huang, S.-L. Developing a Sustainable Long-Term Ageing Health Care System Using the DANP-MV Model: Empirical Case of Taiwan. Int. J. Environ. Res. Public Health 2019, 16, 1349. [CrossRef]

18. Zhu, B.-W.; Zhang, J.-R.; Tzeng, G.-H.; Huang, S.-L.; Xiong, L. Public Open Space Development for Elderly People by Using the DANP-V Model to Establish Continuous Improvement Strategies towards a Sustainable and Healthy Aging Society. Sustainability 2017, 9, 420. [CrossRef]

19. Prange, C. Organizational Learning and the Learning Organization. In Organizational Learning-Desperately Seeking Theory; Easterby-Smith, M., Burgoyne, J., Araujo, L., Eds.; SAGE: London, UK, 1999; pp. 59-74.

20. Huysman, M. Balancing Biases: A Critical Review of the Literature on Organizational Learning. In Organizational Learning and the Learning Organization: Developments in Theory and Practice; Easterby-Smith, M., Araujo, L., Burgoyne, J., Eds.; SAGE: London, UK, 1999; pp. 59-74.

21. Hystad, P.W.; Keller, P.C. Towards a Destination Tourism Disaster Management Framework: Long-Term Lessons from a Forest Fire Disaster. Tour. Manag. 2008, 29, 151-162. [CrossRef]

22. Argyris, C. On Organizational Learning; Wiley: Oxford, UK; Malden, MA, USA, 1999.

23. Wang, J. Developing Organizational Learning Capacity in Crisis Management. Adv. Dev. Hum. Resour. 2008, 10, 425-445. [CrossRef]

24. Borodzicz, E.; Haperen, K.V. Individual and Group Learning in Crisis Simulations. J. Contingencies Crisis Manag. 2002, 10, $139-147$. [CrossRef]

25. Henderson, J. Managing a Tourism Crisis in Southeast Asia. Int. J. Hosp. Tour. Adm. 2002, 3, 85-105. [CrossRef]

26. Hatakenaka, S.; Carroll, J.S. Driving Organizational Change in the Midst of Crisis. J. MIT Sloan 2001, 42, 70-79.

27. Faulkner, B.; Vikulov, S. Katherine, Washed out One Day, Back on Track the next: A Post-Mortem of a Tourism Disaster. Tour. Manag. 2001, 22, 331-344. [CrossRef]

28. Simon, L.; Pauchant, T. Developing the Three Levels of Learning in Crisis Management: A Case Study of the Hagersville Tire Fire. J. Rev. Bus. 2000, 21, 6-11.

29. Elliott, D.; Smith, D.; Frosdick, S.; Walley, L. Sport and Safety Management. In Waiting for the Next One: Management Attitudes to Safety in the UK Football Industry; Butterworth-Heinemann: Oxford, UK, 1997; pp. 85-107.

30. Richardson, B. Crisis Management and Management Strategy-Time to "Loop the Loop"? Disaster Prev. Manag. Int. J. 1994, 3, 59-80. [CrossRef]

31. Blake, A.; Sinclair, M.T. Tourism Crisis Management: US Response to September 11. Ann. Tour. Res. 2003, 30, 813-832. [CrossRef]

32. Gu, H.; Wall, G. Sars in China: Tourism Impacts and Market Rejuvenation. Tour. Anal. 2006, 11, 367-379. [CrossRef]

33. Huang, J.-H.; Min, J.C.H. Earthquake Devastation and Recovery in Tourism: The Taiwan Case. Tour. Manag. 2002, 23, 145-154. [CrossRef]

34. Cró, S.; Martins, A.M. Structural Breaks in International Tourism Demand: Are They Caused by Crises or Disasters? Tour. Manag. 2017, 63, 3-9. [CrossRef] [PubMed]

35. Boin, A.; Mcconnell, A. Preparing for Critical Infrastructure Breakdowns: The Limits of Crisis Management and the Need for Resilience. J. Contingencies Crisis Manag. 2007, 15, 50-59. [CrossRef]

36. Chan, T.Y.J. A Study on Crisis Management in the Travel Agency Sector in Hong Kong. Ph.D. Thesis, Hong Kong Polytechnic University, Hong Kong, China, 2014.

37. Hall, C.M. Crisis Events in Tourism: Subjects of Crisis in Tourism. Curr. Issues Tour. 2010, 13, 401-417. [CrossRef]

38. Sonmez, S.F. Managing Tourism Crises: A Guidebook; Clemson University: Clemson, SC, USA, 1994.

39. Perl, Y.; Israeli, A.A. Crisis Management in the Travel Agency Sector: A Case Study. J. Vacat. Mark. 2011, 17, 115-125. [CrossRef]

40. Campiranon, K.; Scott, N. Critical Success Factors for Crisis Recovery Management: A Case Study of Phuket Hotels. J. Travel Tour. Mark. 2014, 31, 313-326. [CrossRef]

41. Henderson, J.C. Communicating in a Crisis: Flight SQ 006. Tour. Manag. 2003, 24, 279-287. [CrossRef]

42. Ritchie, B.W. Chaos, Crises and Disasters: A Strategic Approach to Crisis Management in the Tourism Industry. Tour. Manag. 2004, 25, 669-683. [CrossRef] 
43. Ritchie, B.W.; Jiang, Y. A Review of Research on Tourism Risk, Crisis and Disaster Management: Launching the Annals of Tourism Research Curated Collection on Tourism Risk, Crisis and Disaster Management. Ann. Tour. Res. 2019, 79, 102812. [CrossRef]

44. Kanel, K. A Guide to Crisis Intervention, 5th ed.; Cengage Learning: Pacific Grove, CA, USA, 2014.

45. James, R.K.; Gilliland, B.E. Crisis Intervention Strategies, 8th ed.; Cengage Learning: Boston, MA, USA, 2016.

46. Thompson, R.A. Crisis Intervention and Crisis Management: Strategies That Work in Schools and Communities; Routledge: New York, NY, USA, 2004. [CrossRef]

47. Potter, D.; Stevens, J.A.; LaBerteaux, P. Practical Concepts and Training Exercises for Crisis Intervention Teams: Including Role-Plays and Interactive Games, 2nd ed.; Chevron Publishing Corporation: Ellicott City, MD, USA, 2005.

48. Collins, B.G.; Collins, T.M. Crisis and Trauma: Developmental-Ecological Intervention; Lahaska Press: Boston, MA, USA, 2005.

49. Lewis, J.A.; Lewis, M.D.; Daniels, J.A. Community Counseling: Empowerment Strategies for a Diverse Society; Thomson, Brooks/Cole: Pacific Grove, CA, USA, 2003.

50. Heller, K.; Monahan, J. Psychology and Community Change; Dorsey Press: Pacific Grove, CA, USA, 1977.

51. Myer, R.A.; James, R.K. CD-ROM and Workbook for Crisis Intervention, Revised Version, 1st ed.; Cengage Learning: Belmont, CA, USA, 2006.

52. Hershenson, D.B.; Power, P.W.; Waldo, M. Community Counseling: Contemporary Theory and Practice; Waveland Pr Inc.: Prospect Heights, IL, USA, 2003.

53. Chen, G.; Lai, N.; Chien, C.; Lee, M. Crisis Management: Theory and Practice, Community Counseling Conference; Kao Hsung Normal University: Gaoxiong City, Taiwan, 2005.

54. Daiy, A.K.; Shen, K.-Y.; Huang, J.-Y.; Lin, T.M.-Y. A Hybrid MCDM Model for Evaluating Open Banking Business Partners. Mathematics 2021, 9, 587. [CrossRef]

55. Liu, C.-H. Schemes for Enhancing Taiwanese Cruise PAK Relationships Using the Hybrid MADM Model. Tour. Manag. 2018, 69, 510-522. [CrossRef]

56. Dey, S.; Kumar, A.; Ray, A.; Pradhan, B.B. Supplier Selection: Integrated Theory Using DEMATEL and Quality Function Deployment Methodology. Procedia Eng. 2012, 38, 3560-3565. [CrossRef]

57. Fontela, E.; Gabus, A. The DEMATEL Observer (DEMATEL 1976 Report); Battelle Geneva Research Center: Geneva, Switzerland, 1976.

58. Gabus, A.; Fontela, E. Perceptions of the World Problematique: Communication Procedure, Communicating with Those Bearing Collective Responsibility; DEMATEL Report No. 1; Battelle Geneva Research Center: Geneva, Switzerland, 1973.

59. Liu, C.-H.; Tzeng, G.-H.; Lee, M.-H.; Tseng, H.-L.; Lee, P.-Y. Using a Hybrid MCDM Model Combining Fuzzy DEMATEL Technique to Examine the Job Stress of Coach Driver. In Intelligent Decision Technologies; Watada, J., Watanabe, T., Phillips-Wren, G., Howlett, R.J., Jain, L.C., Eds.; Smart Innovation, Systems and Technologies; Springer: Berlin/Heidelberg, Germany, 2012; Volume 16, pp. 149-156. [CrossRef]

60. Saaty, T.L. Decision Making with Dependence and Feedback: The Analytic Network Process.; RWS Publications: Pittsburgh, PA, USA, 1996.

61. Opricovic, S.; Tzeng, G.-H. Extended VIKOR Method in Comparison with Outranking Methods. Eur. J. Oper. Res. 2007, 178, 514-529. [CrossRef]

62. Opricovic, S.; Tzeng, G.-H. Compromise Solution by MCDM Methods: A Comparative Analysis of VIKOR and TOPSIS. Eur. J. Oper. Res. 2004, 156, 445-455. [CrossRef]

63. Opricovic, S. Multicriteria Optimization of Civil. Engineering Systems; Faculty of Civil Engineering: Belgrade, Serbia, 1998.

64. Opricovic, S.; Tzeng, G.-H. Multicriteria Planning of Post-Earthquake Sustainable Reconstruction. Comput. Aided Civ. Infrastruct. Eng. 2002, 17, 211-220. [CrossRef]

65. DeVellis, R.F. Scale Development: Theory and Applications; SAGE Publications: London, UK, 2011.

66. Faugier, J.; Sargeant, M. Sampling Hard to Reach Populations. J. Adv. Nurs. 1997, 26, 790-797. [CrossRef]

67. Näswall, K.; Kuntz, J.; Hodliffe, M.; Malinen, S. Employee Resilience Scale (EmpRes): Technical Report. 2013. Available online: https:/ /ir.canterbury.ac.nz/handle/10092/9469 (accessed on 2 August 2021). 